Reprinted from Myers, J. E., Sweeney, T. J., \& Witmer, M. (2000). The Wheel of Wellness Counseling for Wellness:

A holistic model for treatment planning. Journal of Counseling and Development, 78(3), 251-266. The American Counseling Association. Reprinted with permission. No further reproduction authorized without written permission from the American Counseling Association:

http://www.counseling.org/

\title{
The Wheel of Wellness Counseling for Wellness: A Holistic Model for Treatment Planning
}

\author{
Jane E. Myers, Thomas J. Sweeney, and J. Melvin Witmer
}

\begin{abstract}
A holistic model of wellness and prevention over the life span was presented by T. J. Sweeney and J. M. Witmer (1991) and J. M. Witmer and T. J. Sweeney (1992). Recent advances in research and theory related to wellness support modifications of the original model. The foundation for the model is examined, research related to each component is explored, and implications for use of the model as a basis for counseling interventions are presented.
\end{abstract}

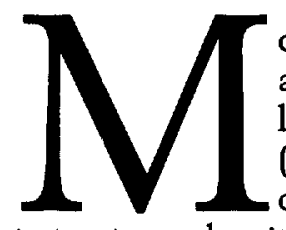
ore than half and as many as two thirds of all premature deaths in the U.S. are due to lifestyle factors that can be modified (Shannon \& Pyle, 1993). However, while over $75 \%$ of health care dollars are spent to treat people with chronic diseases, less than $1 \%$ of federal funds and $2 \%$ of state funds are spent to prevent these diseases from occurring (Encyclopedia of Social Work, 1995). In fact, the total costs of illness increased from $5 \%$ to $12 \%$ of the gross national product in the 30-year period from 1960 to 1990 (U.S. Department of Health and Human Services [DHHS], 1990). The federal response to this situation is described in the report, Healthy People 2000 (U.S. DHHS, 1990), which sets health promotion and disease prevention goals for the nation. By 1996, only two thirds of these goals had shown any improvement and none had been totally met (Kaufmann, 1997). A paradigm shift in medicine away from disease and illness and toward an emphasis on wellness and health is occurring (Randall, 1996), but clearly there is room for improvement.

A new paradigm of wellness has emerged in the last decade as an alternative to the traditional, illness-based medical model for treatment of mental and physical disorders. Although most of the existing definitions and models of wellness are based in physical health professions (e.g., Hettler, 1984), the Wheel of Wellness first described by Sweeney and Witmer (1991) and Witmer and Sweeney (1992) is unique in having both a multidisciplinary focus and theoretical grounding in theories of human growth and behavior. These authors proposed a holistic model of wellness and prevention over the life span and summarized a broad array of literature from multiple disciplines supporting the elements of the model. However, they did not illustrate the use of the model as a basis for counseling interventions.

Recent research in medical as well as social and psychological sciences, combined with additional research and use of the Wheel of Wellness in counseling, suggest that several characteristics of healthy people were either lacking sufficient emphasis or missing from the model as originally presented. The purpose of this article is to describe the revised model, review research that establishes each component as a characteristic of healthy people, and discuss the use of the Wheel of Wellness as a basis for developing personal wellness plans to help clients achieve greater wellness. A case example from our practice is included to demonstrate the application of the model in work with clients. The case illustration underscores the relevance of our approach in a world increasingly dominated by managed care. At first glance, the practitioner struggling daily with third party payments may find little of value in a wellness approach. However, on closer examination, three reasons may be cited to encourage this emphasis.

First, the failure of the current health care delivery system to meet the needs of Americans and the public pressure for health care reform is well documented (Zis, Jacobs, \& Shapiro, 1996). Traditional delivery systems have failed both economically and in terms of care to meet the needs of millions of individuals who are uninsured or underinsured.

Jane E. Myers is a professor in the Department of Counseling and Educational Development at The University of North Carolina at Greensboro. Thomas J. Sweeney is Professor Emeritus, and J. Melvin Witmer is Professor Emeritus, both in Counselor Education at Ohio University in Athens. Correspondence regarding this article should be sent to Jane E. Myers, Department of Counseling \& Educational Development The University of North Carolina at Greensboro, PO Box 26171, 222 Curry Building, Greensboro, NC 27402-6171 (e-mail: jemyers@uncg.edu). 
Second, in response to this situation, a variety of programs have emerged that represent new directions in health care. An example is Dean Ornish's nonsurgical, nonpharmacological approach to reversing heart disease, a program so successful that it receives funding from Medicare (Sternberg, 1997). The success of this program lies in the use of nontraditional "therapies," including stress management, techniques for improving communication and interpersonal relationships, modification of lifestyle factors such as exercise and diet, meditation, and communication with a personally defined higher power. Ornish's program has been credited with savings of up to $\$ 10,000$ per patient, in addition to saving lives.

Third, and perhaps most important to counselors, is the fact that the emerging paradigm in health care stresses prevention, early intervention, and alternative methods of remediationstrategies that are in the purview of skills of professionals in our field. It is noteworthy that Smith (1997), in a recent national survey of counselors' participation in managed care, identified several unique competencies of professional counselors that are "particularly useful in the managed care environment" (p. 7). These include a prevention focus that incorporates a wellness, holistic, and developmental orientation, and treatment planning that builds on the strengths and assets of our clients. Consistent with this finding, we believe that the Wheel of Wellness provides a comprehensive model and methods for counselors to incorporate in their existing repertoire of knowledge and skills to make them even more effective care providers in the managed care setting.

\section{THE WHEEL OF WEUNESS}

In writing about individual psychology, Adler (1927/1954) noted the importance of holism in understanding the individual. Furthermore, he noted that "it is always necessary to look for ... reciprocal actions of the mind on the body, for both of them are parts of the whole with which we should be concerned" (Ansbacher \& Ansbacher, 1967, p. 255). In studying characteristics of healthy people, Maslow (1970) concluded that striving toward self-actualization, growth, and excellence is a universal human tendency and overarching life purpose. In earlier writings, we proposed a holistic model of wellness and prevention over the life span based on the work of these authors and others who studied characteristics of healthy people (Sweeney \& Witmer, 1991; Witmer \& Sweeney, 1992; Witmer, Sweeney, \& Myers, 1998). We define wellness as a way of life oriented toward optimal health and well-being in which body, mind, and spirit are integrated by the individual to live more fully within the human and natural community. Ideally, it is the optimum state of health and well-being that each individual is capable of achieving. In developing this definition and wellness model, we incorporated theoretical concepts from multiple disciplines. The results of research as well as theoretical perspectives from personality, social, clinical, health, and developmental psychology were foundations for the model, as were stress management, behavioral medicine, psychoneuroimmunology, ecology, and contextualism.
The original model proposed five life tasks, depicted in a wheel with spokes that are interrelated and interconnected. These five tasks were spirituality, self-regulation, work, friendship, and love. Based on research using an assessment instrument developed from the model (the Wellness Evaluation of Lifestyle, or WEL), specifically the results of a factor analysis on a sample of more than 3,000 people (Hattie, Myers, \& Sweeney, 1999), the life task of work was subdivided into the two tasks of work and leisure. The life task of self-regulation originally included seven components. After using the model and the WEL in research and clinical practice, this task was renamed "self-direction," and 12 subtasks were clearly defined. These 12 subtasks are as follows: (a) sense of worth, (b) sense of control, (c) realistic beliefs, (d) emotional awareness and coping, (e) problem solving and creativity, $(f)$ sense of humor, (g) nutrition, (h) exercise, (i) self-care, (j) stress management, (k) gender identity, and (1) cultural identity. These life tasks interact dynamically with various life forces, including but not limited to family, community, religion, education, government, media, and business/industry. Global events, whether of natural (e.g., floods, famines) or human (e.g., wars) origin, have an impact on the life forces and life tasks depicted in the model. The revised model is shown in Figure 1, and abbreviated definitions of each dimension of wellness in the model are provided in Appendix A.

Changes in one area of wellness affect other areas, in both positive and negative directions. Support for this interaction between various components of the Wheel of Wellness is found in the literature (e.g., Cowen, 1991), as is evidence that different components of wellness are more or less salient at different points in the life span (e.g., Kaufmann, 1997; Ryff \& Heidrich, 1997). Healthy functioning occurs on a developmental continuum, and healthy behaviors at one point in life affect subsequent development and functioning as well. Gender differences in many of the components of wellness as well as cultural differences have also been identified. Including these studies is beyond the scope of the present literature review. Our intent here is to support the identification of each component as a characteristic of healthy functioning, a major component of wellness, and a viable area for counseling interventions. Our emphasis is on the five major life tasks and subtasks because these are considered to be directly amenable to interventions by counselors.

\section{Life Task 1: Spirituality}

Spirituality is defined as an awareness of a being or force that transcends the material aspects of life and gives a deep sense of wholeness or connectedness to the universe. A distinction is made between spirituality, a broad concept representing one's personal beliefs and values, and religiosity, a narrower concept that refers to institutional beliefs and behaviors and that is a part of the broader concept of spirituality (Ingersoll, 1994). Religiosity is a public matter, often expressed in group religious participation, whereas spirituality is more a private issue that may or may not be expressed publicly (Hinterkopf, 


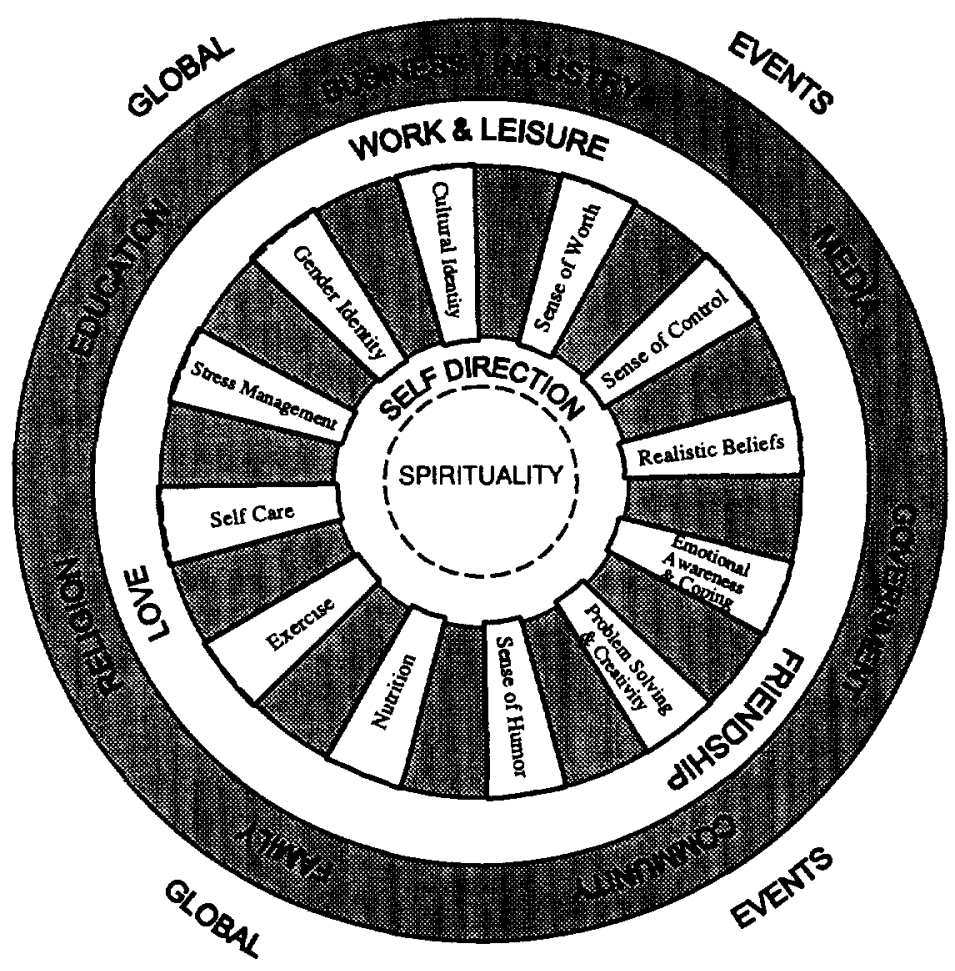

FIGURE 1

The Wheel of Wellness

Note. From The Wheel of Wellness (p. 10), by J. M. Witmer, T. J. Sweeney, and J. E. Myers, 1998, Greensboro, NC: Authors. Copyright 1998 by Witmer et al. Reprinted with permission.

1994). Spirituality is conceptualized as the core characteristic of healthy people (Seaward, 1995) and the source of all other dimensions of wellness (Chandler, Holden, \& Kolander, 1992).

Lightsey (1996) completed a comprehensive review of the relationship between psychological resources and wellness, noting that four resources-positive thoughts, hardiness, generalized self-efficacy, and optimism-have been strongly correlated with well-being and resistance to stress. Both positive thoughts and optimism are components of spirituality, as defined here. The relationship between subjective well-being and optimism is clearly positive, such that people with a high sense of well-being have a tendency to experience events in a positive manner.

Lindgren and Coursey (1995) reviewed the literature on spirituality and mental illness, noting that spiritual supportsimilar to social support-may have "a stress-buffering effect" (p. 93). This effect is due both to cognitive mediation of stressful events and to emotional support through organized religious or spiritual practices with others (Koenig, 1991). Recent studies suggest that there is a significant positive relationship between spirituality, of which religion is only one part, mental health (Westgate, 1996), physical health (Larson \& Larson, 1991), life satisfaction (Chumbler, 1996), and wellness (Maher \& Hunt, 1993; Oleckno \& Blacconiere, 1991).

\section{Life Task 2: Self-Direction}

Self-direction is the manner in which an individual regulates, disciplines, and directs the self in daily activities and in pursuit of long-range goals (Hafen, Franksen, Karren, \& Hooker, 1992; Pelletier, 1994). It refers to a sense of mindfulness and intentionality in meeting the major tasks of life. The patterns of behavior and methods of adjustment to life that make up self-direction are sometimes referred to as "positive personality traits" that give one a stress-resistant personality (Perls \& Silver, 1999).

Sense of worth. Sense of worth is variously referred to in the literature as "self-concept," "self-esteem," and "self-worth" (Branden, 1994). Hattie (1992) defined self-concept to include "descriptions, prescriptions, and expectations" (p. 4l) about our self. These three cognitive appraisals are integrated through a process of self-enhancement that reflects confirmation as well as disconfirmation of our self-appraisals from 
others. High self-esteem results when "we consider aspects of our life as important and ... we have the confidence to fulfill our expectations" (Hattie, 1992, p. 54).

The person who has high self-esteem is excited by new challenges and seeks self-actualization (Yau, 1991). Hafen et al. (1992) reviewed the literature on sense of worth and concluded that positive self-esteem is a preventive factor for illness, enhances recovery from illness, and enhances overall well-being. In virtually all studies of positive mental health, the key factors that emerge are a positive self-concept, a sense of autonomy, social support, and an internal locus of control or sense of self-efficacy (Compton, Smith, Cornish, \& Qualls, 1996). Self-esteem is a more significant predictor of life satisfaction in individualist countries, such as the United States, than it is in those with a collectivist orientation, where relationship harmony seems to be more closely related to selfesteem in predicting life satisfaction (Kwan, Bond, \& Singelis, 1997).

Sense of control. The results of numerous studies indicate that people experience positive outcomes when they perceive themselves as having an impact on what happens to them and experience negative outcomes (e.g., depression) when they perceive a lack of personal control (Beckingham \& Watt, 1995). Perceived control is associated with emotional well-being, successful coping with stress, better physical health, and better mental health over the life span (Daniels \& Guppy, 1994; Pelletier, 1994), as well as psychological hardiness (Kobasa, 1979). Having an internal locus of control has been associated with lower levels of anxiety and depression and higher levels of self-esteem and life satisfaction (Cvetanovski \& Jex, 1994). Higher levels of perceived self-control predict healthier behavior (Birkimer, Johnston, \& Berry, 1993), including exercise participation (Ali, 1996) and weight control (Walcott-McQuigg, Sullivan, Dan, \& Logan, 1995), and in turn are affected by participation in positive health practices such as exercise (Donaldson \& Blanchard, 1995; Fontane, 1996).

Realistic beliefs. Epictetus stated that "people are disturbed not by things, but by the view which they take of them" (Ellis, 1984, p. 200). Ellis (1973) noted that people have a tendency to disturb themselves through the perpetuation of their irrational beliefs, the major ones being (a) I must be loved or approved of by everyone, (b) I must be perfectly competent and productive, (c) it is a catastrophe when things go other than the way one might wish, (d) life must be absolutely fair, and (e) it is better to avoid life's difficulties than to take responsibility for changing them.

Healthy people are able to process information accurately and perceive reality as it is rather than as they wish it to be. People who have realistic beliefs are able to accept themselves as imperfect. Adler referred to "internal beliefs" as one's private logic that in turn guides both the feelings and the behaviors of the individual (Sweeney, 1998). The greater the discrepancy between one's private logic and reality, the greater the potential for unhealthy behaviors in response to life events. In fact, the results of three longitudinal studies suggest that accurate appraisals of the self and the social environment are essential to positive mental health (Covin, Block, \& Funder, 1995).

Emotional awareness and coping. To experience and positively manage one's emotions is one index of healthy functioning. Many individuals are limited in their ability both to experience and to express joy, anger, affection, and related human emotions. As a consequence, the quality and quantity of relationship events within their lives are limited. By contrast, healthy functioning is reflected in rich, varied, and frequent expressions and responses to people and events within one's daily experiences.

Numerous studies report a significant relationship between thoughts, feelings, and illness (Witmer, 1996), with positive emotionality being a major component of mental health and subjective well-being (Compton et al., 1996), a negative correlate with depression (Ingram, Atkinson, Slater, Saccuzzo, \& Garfin, 1990), and an accurate predictor of physical as well as psychological health. Negative emotions such as anxiety and depression are associated with immune system suppression and a consequent increase in the potential for illness (Temoshok \& Dreher, 1992). Hostility has been shown to be a major contributor to high blood pressure, coronary artery disease, and death, particularly among people with a TypeA personality (Hafen et al., 1992). On the other hand, the appropriate expression of negative emotions combined with the presence of positive emotions seems to strengthen immune function (Dillon, Minchoff, \& Baker, 1985).

Problem solving and creativity. Intellectual stimulation, including problem solving and creativity, is necessary for healthy brain functioning and hence quality of life across the life span (i.e., "use it or lose it"; Pelletier, 1994). Montague (1981) suggested that all thinking involves problem solving. Furthermore, he suggested that the need to think soundly is innate and composed of several traits, including the need to know, the need to learn, the need to organize, curiosity, and a sense of wonder. Elliott and Marmarosh (1994) compared effective and ineffective problem solvers and found that those who self-reported as effective had more positive health expectancies, higher expectancies for control, fewer irrational beliefs, and a lower tendency toward self-criticism than did ineffective problem solvers. Effective problem solving also correlates with reduced anxiety and depression, increased stress hardiness, and overall psychological adjustment (Benson \& Stuart, 1992).

Creativity has been identified as a universal characteristic of self-actualizing people, all of whom demonstrate originality, expressiveness, imagination, inventiveness, and problem-solving ability (Maslow, 1970). It is a multidimensional phenomenon involving the ability to develop new or different concepts, ideas, structures, or products. Creativity is optimized in individuals with high self-esteem (Yau, 1991) and has a positive effect on life satisfaction, mental health, and overall wellness (Goff, 1993).

Sense of humor. Humor, a cognitive and emotional process, includes both recognition and appreciation of humorous stimuli and creation of humorous stimuli (Solomon, 1996). Especially when accompanied by laughter, humor 
causes the skeletal muscles to relax, boosts the immune system, increases heart rate, stimulates circulation, oxygenates the blood, "massages" the vital organs, aids digestion, and releases chemicals (endorphins) into the brain that enhance a sense of well-being (Erdman, 1991). Humor has been associated with reduced depression and pain relief (Carroll, 1990), higher levels of self-esteem and lower perceived levels of stress (Kuiper \& Martin, 1993), more positive and self-protective cognitive appraisals when dealing with stress, and a greater positive response to both positive and negative life events (Martin, Kuiper, Olinger, \& Dance, 1993). Humor facilitates the enjoyment of positive life experiences (Martin et al., 1993) and has a positive effect on physical health (Solomon, 1996).

Humor also allows cognitive shifts that help individuals gain insight into their personal problems (Burns, 1989), increase social cohesion (Richman, 1995), defuse conflicts, and reduce feelings of hostility (Morreall, 1991). However, humor that has a put-down component is related to health problems (Carroll, 1990), whereas a positive sense of humor enhances healthy aging (Solomon, 1996). Humor promotes creativity, improves negotiating and decision-making skills, improves individual and group performance, relieves stress, and bestows a sense of power (Hafen et al., 1992).

Nutrition. There is a clear relationship between what we eat and our health, moods, performance, and longevity (Wurtman \& Suffes, 1996). The eating and drinking habits of Americans have been implicated in 6 of the 10 leading causes of death, including the fact that 1 in 3 Americans is considered to be overweight (U.S. DHHS, 1996). Toner and Morris (1992) examined the relationship among selfactualization, social support, and dietary intake, noting that all three factors influenced dietary quality. Alternately, factors such as loneliness, poor physical health, and lack of meaningful social contacts result in lowered dietary quality (Walker \& Beauchene, 1991). Successful aging requires a nutritionally complete diet and adequate exercise (Nelson \& Franzi, 1989), suggesting the need for a life span approach to nutritional wellness.

Exercise. Regular physical activity, or exercise, is viewed as essential in preventing disease and enhancing health (Ory \& Cox, 1994) and is "a key ingredient to healthy aging" (U.S. DHHS, 1990, p. 587). The benefits of exercise for physical as well as psychological well-being have been clearly established (Gleser \& Mendelberg, 1990). Exercise increases strength as well as self-confidence (Fontane, 1996) and selfesteem (International Society of Sport Psychology, 1992). In addition, there is a significant correlation between physical fitness and positive emotionality (Brandon \& Loftin, 1991) as well as enhanced cognitive functioning (Wykoff, 1993). Exercise training has been shown to significantly decrease state-trait anxiety scores (S. R. Cramer, Nieman, \& Lee, 1991), decrease mild depression, reduce stress, and beneficially affect a variety of chronic illnesses (International Society of Sport Psychology, 1992). In addition, exercise may help to preserve a sense of social identity (Fontane, 1996).
Self-care. Taking responsibility for one's wellness requires personal habits of preventive behavior as well as remedial treatment. Three aspects of self-care constitute this dimension: safety habits that we learn to protect ourselves from injury or death; periodic physical, medical, and dental checkups; and avoiding harmful substances, both those that we might ingest and toxic substances in the environment. Positive self-care improves the quality of life and extends longevity, whereas failure to engage in preventive self-care habits leads to decline in physical functioning and increased mortality (Broman, 1993).

Stress management. Stress affects both psychological and physiological functioning and has a specific depressant effect on immune system functioning (Baum, Herberman, \& Cohen, 1995). People who are stress-resistant experience more positive and beneficial immune system responses, greater resistance to psychosocial stressors (Green \& Shellenberger, 1991), and a more internal locus of control (Keita \& Jones, 1990). They also experience more positive mental health and greater physical health (Compton et al., 1996). On the other hand, the effects of chronic stress are major contributors to escalating health care costs, reaching almost $\$ 150$ billion annually in the early 1990s (McCain \& Smith, 1994).

Ebersole and Hess (1994) defined stress management as the ability to identify stressors in one's life and to reduce or minimize stress by using strategies of stress reduction. The negative effects of stress can be reduced or eliminated through self-regulatory strategies such as biofeedback and relaxation techniques (Chen, 1995), social support (Keita \& Jones, 1990), and behaviorial/environmental methods such as assertiveness and communication skills training, changing mistaken ideas, problem solving, and exercise (Brandon \& Loftin, 1991).

Gender identity. Gender identity, a "basic, existential conviction that one is male or female" (Spence \& Sawin, 1985, p. 59), refers to subjective feelings of maleness or femaleness and is culturally constructed or defined (Golombok \& Fivush, 1994). Satisfaction with being a male or a female and a sense of confidence or comfort in being male or female affect one's subjective feelings of gender identity (Basow, 1992). Gender role identity, in contrast to gender identity, reflects one's identification with "the social prescriptions or stereotypes associated with each sex, to which an individual may or may not conform" (Hyuck, 1990, p. 124) rather than the introspective, selfdefinition of one's gender.

Gender role socialization, a process that begins at birth and continues throughout the life span, results in culturally appropriate gender role behaviors being rewarded for both men and women (Cowher, 1995). For example, Maccoby (1990) suggested that men are rewarded for engaging in traditionally "masculine" behaviors such as achievement, competition, and independence, whereas women are rewarded for engaging in nurturing, supportive, interdependent, and empathic relationship behaviors. These gender differences have been linked to wellness as well as illness in adulthood. For example, American women more readily report their illnesses than do men, use medical and mental health systems more fre- 
quently than do men, and outlive men by an average of 7 years (Nicholas, Gobble, Crose, \& Frank, 1992).

Cultural identity. Culture may be broadly defined as "a multidimensional concept that encompasses the collective reality of a group of people" (Lee, 1997, p. 11). Cultural identity, a concept that incorporates racial identity, acculturation, and an appreciation for the unique aspects of one's culture, is positively related to well-being (Sue \& Sue, 1990). Cultural identity is a positive personal strength that enhances growth and development across the life span (Fontes, 1991).

Cultural identity affects self-perceived health and wellness because the concepts of health differ according to culture (Allinger \& Causey, 1995). For example, self-esteem in African American children is related to cultural identity, and cultural identity is more closely related to psychosocial adjustment in these children than is self-esteem (Whaley, 1993). Psychological stress and behavioral deviance are culturally defined and are often explained in culturally specific religious or spiritual frameworks (Lee, 1996). On the other hand, happiness is explained in a Western context as being positively correlated with independence and an internal locus of control. In Eastern societies, the subjective evaluation of happiness places greater emphasis on relationship harmony and interpersonal contentment (Lu \& Shih, 1997).

\section{Life Task 3: Work and Leisure}

Work and leisure provide an opportunity for pleasurable experiences that are intrinsically satisfying and provide a sense of accomplishment (McDaniels \& Gysbers, 1992). They challenge or engage our senses, skills, and interests, frequently absorbing us in activities in a state of consciousness called "flow." This is an optimal state in which an individual loses awareness of self and time while being highly engaged in the task at hand. Excitement and joy are enhanced while anxiety and boredom are minimized (Csikszentmihalyi, 1990).

Work. Work serves the major functions of economic support, psychological purposes, and social benefits (Herr \& Cramer, 1988). It was considered by Adler (1927/1954) to be the most important task for maintenance of life. He further defined work as an activity that is useful to the community (others), whether for monetary gain or otherwise. Work satisfaction-composed of challenge, financial reward, coworker relations, and working conditions-is one of the best predictors of longevity as well as perceived quality of life (Pelletier, 1994). People who view their career as a calling tend to experience the highest work satisfaction (Wrzesniewski, McCauley, Rozin, \& Schwartz, 1997). Ross and Mirowski (1996) found that recognition from others in the work environment increases sense of control for men, whereas earnings have a greater effect on psychological wellbeing for women. Feelings of competence in work tasks also have a positive effect on life satisfaction (Lam, Foong, \& Moo, 1995), whereas work experiences and work outcomes are consistently and positively related to self-reported emotional well-being (Burke \& McKeen, 1995).
The meaning of work and time commitments related to work must be balanced in a healthy individual with time, energy, and satisfaction devoted to family and friends (Davidson \& Gilbert, 1993). For example, in a study of working women, Napholz (1995) found that those whose work had first or equal priority to their home life had higher depression and role conflict scores than did those who put their relationships first. Job flexibility is positively correlated with overall emotional well-being for both men and women (Ulione, 1996). The following also correlate positively with emotional well-being: having a valued social position at work, experiencing clarity in regard to work assignments, and feeling a sense of control in relation to one's environment and assignments (Warr, 1994). In addition, job security is essential to the psychological well-being of employed individuals (Kuhnert \& Palmer, 1991). There is some evidence that factors affecting positive well-being in the work environment may also be obtained through participation in leisure activities (Haworth \& Hill, 1992).

Leisure. Adler referred to leisure, or play, as a "minor life task" (Hawes \& Blanchard, 1993). Leisure activities, including physical, social, intellectual, volunteer, and creative (McDaniels \& Gysbers, 1992), have a positive effect on self-esteem (Reitzes, Mutran, \& Verrill, 1995) and perceived wellness (Ragheb, 1993). Zimmer and Lin (1996) reviewed studies of the relationship between leisure activity and well-being among older adults and concluded that leisure activity increases one's sense of emotional well-being. Additional studies of the relationship between leisure and well-being have found positive correlations with leisure activities (Ragheb, 1993) and the role of personality in choice of activities (Coleman \& Iso-Ahola, 1993). Life satisfaction also is influenced by leisure congruence, defined as the selection of leisure activities consistent with one's personality type (Melamed, Meir, \& Samson, 1995). Participation in certain types of leisure activities, notably exercise, is an important means of reducing the effects of stress. Leisure activities also mediate the effects of stress by providing social support and through developing psychological hardiness (Coleman \& Iso-Ahola, 1993).

\section{Life Task 4: Friendship}

The friendship life task incorporates all of one's social relationships that involve a connection with others, either individually or in community, but do not have a marital, sexual, or familial commitment. Adler (1927/1954) considered social interest as innate to human nature, noting that we are all born with the capacity and need to be connected with each other. Zauszniewski (1994) explained Adler's concept of social interest as a"health-seeking mechanism which describes one's innate potential for showing concern for and valuing others" (p. 160). Empathy, cooperation, and altruism are all manifestations of social interest. Those who regularly devote time to helping others are as likely to experience health benefits as those who exercise or meditate (Luks, 1992). Baumeister and Leary (1995) conducted a review of the literature in this area and concluded that the desire 
for interpersonal attachments is a fundamental human motivation. This motivation is reflected in the need for frequent, positive interactions with the same people and the search for a long-term, stable, and caring support network.

There is a strong positive connection between friendship quality and sense of well-being (Ishii-Kuntz, 1990), including physical as well as mental health (Ulione, 1996) across the life span (Hartup \& Stevens, 1997). Alternately, dissatisfaction with close friendships or intimate relationships is predictive of depression (Cconey \& Kurz, 1996). "Perceived adequacy of interactions with friends, in terms of the amount and meaning of the interaction and the level of satisfaction with it, are significant predictors of happiness" (Adams \& Bleizner, 1995, p. 219). People with satisfying social relationships are more likely to avoid health damaging behaviors, such as smoking, drinking, and not using seat belts (Broman, 1993), and are more likely to consume a nutritious and healthy diet (Toner \& Morris, 1992).

Social support, the degree to which a person's basic social needs are met through interaction with others (Cohen \& Syme, 1985), is positively correlated with both physical and emotional health (Ulione, 1996) and provides a buffer against stress (Dalgard, Bjork, \& Tambs, 1995). Friendships enhance self-esteem (D. Cramer, 1994), such that friendship satisfaction is among the strongest predictors of positive self-esteem (Diener \& Diener, 1995; Lightsey, 1996). Friendships also prevent feelings of loneliness (Thompson \& Heller, 1990) and are essential for positive growth and development (Borenstein, 1996). In contrast, research from various studies shows that people who are socially isolatedthose who are unmarried, divorced, widowed, people with few friends, and people who have few social contacts-are much more likely to die from various diseases than those who have happy, fulfilling social lives (Hafen et al., 1992).

\section{Life Task 5: Love}

Relationships that are formed on the basis of a sustained, longterm, mutual commitment and involve intimacy constitute the life task of love. Characteristics of healthy love relationships include (a) the ability to be intimate, trusting, and selfdisclosing with another person; (b) the ability to receive as well as express affection with significant others; (c) the capacity to experience or convey nonpossessive caring that respects the uniqueness of another; (d) the presence of enduring, stable intimate relationships in one's life; (e) concern for the nurturance and growth of others; and (f) satisfaction with one's sexual life or the perception that one's needs for physical touch and closeness are being met, or both (Myers, Witmer, \& Sweeney, 1998; Sweeney \& Witmer, 1991). The life task of love necessitates having a family or family-like support system that has the following nine characteristics: (a) shared coping and problem-solving skills; (b) commitment to the family; (c) good communication; (d) encouragement of individuals; (e) expression of appreciation; (f) shared religious/spiritual orientation; (g) social connectedness; (h) clear roles; and (i) shared interests, values, and time (Krystan, Moore, \& Zill, 1990).
The feeling of being loved and valued by others, a feeling unrelated to the number or structure of social relationships, has been identified as the core component of social support (Sarason, Shearin, Pierce, \& Sarason, 1987). For those who answer "no" to the question, Do you have anyone who really cares for you? the risk of premature death and disease from all causes is 3 to 5 times higher (Ornish, 1998). Thus, it is not surprising that mortality rates are consistently higher for divorced, single, and widowed individuals of both sexes and all races (Berkman \& Syme, 1979). It is interesting that people who are unhappily married or in negative relationships are less healthy than those who are divorced (Burg \& Seeman, 1994), whereas divorced people have higher rates of heart disease, cancer, pneumonia, high blood pressure, depression, alcoholism, traffic accidents, homicide, suicide, and accidental death than do people who are married (Hafen et al., 1992). Divorced people also have poorer immune system function and are less resistant to disease (Kiecolt-Glaser et al., 1993). These effects are not limited to any one culture. A recent study of Chinese adults, for example, showed that those with the greatest marital maladjustment experienced more psychiatric symptoms, had lower scores on measures of purpose in life, and perceived their health as poor (Shek, 1995).

For men, women, and children, committed relationships provide protection against physical and mental illness, increased longevity, and a greater sense of well-being (Hafen et al., 1992) and promote better physical and emotional responses to stress (Winefield, Winefield, \& Tiggeman, 1992). May and Logan (1993) found that college students who perceived their families as healthy had lifestyles that promoted health and wellness. Alternately, May and Logan found that "students who are actively engaged in a combative relationship with their parents are more likely to experience difficulty in adjusting to college life" (p. 397). Similarly, Lawler, Volk, Viviani, and Mengel (1990) found that adolescents who lived in families that were more cohesive experienced lower depression scores and reported experiencing fewer stressful life events. These findings provide strong support for the importance of counseling to enhance social support and love relationships.

\section{IMPLICATIONS FOR COUNSEUNG}

We have used the Wheel of Wellness in workshops with counselors and other professionals; in classes with undergraduate and graduate students in counseling and other disciplines; and in clinical work with individuals, couples, and groups. We have found it useful in each context. Although work is currently underway with middle school children, what follows is drawn principally from work with young-to-older adults.

Our suggestions for using the Wheel in counseling incorporate four steps, or phases: (1) introduction of the Wheel of Wellness model, including a life span focus; (2) formal or informal assessment, or both, based on the model; (3) intentional interventions to enhance wellness in selected areas of the Wheel; and (4) evaluation, follow-up, and continuation of Steps 2 through 4. 


\section{Phase 1: Introduction of the Wheel of Wellness Model}

The first step in use of the Wheel of Wellness is typically to define wellness, introduce the model, and explain how a focus on healthy living can contribute to overall wellbeing. A copy of the model is placed before the client, and each characteristic in the model is briefly described. The interaction of the components of the model is an important concept when presenting the Wheel. Change in any one area can contribute to or create changes in other areas, and these changes can be for better or worse. We emphasize the point that wellness is a choice and that each choice made toward wellness empowers the client toward even greater happiness and life satisfaction by enhancing overall well-being.

It is important in presenting the model to emphasize the three- or even four-dimensional nature of wellness. We encourage our clients to view the model as a round sphere or globe, with spirituality in the center. If one's sense of spirituality is healthy, the middle of the sphere is round and full and provides a firm foundation or core for the rest of the components of wellness. If one's sense of spirituality is somehow flat, the rest of the sphere cannot be firm and round. Similarly, the tasks of self-direction function metaphorically like the spokes in a wheel. As long as they are strong, the wheel can roll along solidly through time and space. If one or more spokes are defective, as in the broken spokes of a bicycle, the wheel is unable to move smoothly through time and space. It is, in effect, similar to a wheel that is out of balance as it travels roughly along the continuums of time and space.

The Wheel represents the components of wellness over the life span, and attention to each component has consequences that multiply over time. For those who make wellness choices, the cumulative effect over the life span is one of increasing wellness in all dimensions, thereby contributing to quality of life and longevity. We encourage clients to take a life span perspective on their total wellness, reviewing the impact of prior choices in each dimension of wellness, and projecting the future impact of choices made at this time.

Finally, we ask clients to review the model and reflect on the personal meaning of wellness. We encourage them first to seek to achieve a personal definition of wellness, then to reflect on wellness as a process rather than an outcome. Next, we encourage them to study the Wheel and reflect on the personal meaning of each concept. Finally, to personalize their view of wellness further, we encourage informal and sometimes formal assessments of the dimensions of wellness.

\section{Phase 2: Informal and Formal Assessment of the Components of the Wheel of Wellness}

Assessment of the components of the Wheel of Wellness requires a procedure for systematically viewing each dimension and measuring one's wellness on a continuum from not well to high-level wellness. We consider health to be a neutral state in which disease is absent. High level wellness, on the other hand, is a deliberate state in which the process of making choices toward greater wellness becomes self-perpetuating. The purpose of assessment is to provide a basis for developing a personal wellness plan and beginning the process of assuring that change is for the better, with any lifestyle changes designed to contribute to greater total wellness.

A global self-report assessment of a client's functioning in each of the components of the Wheel can be obtained by asking the client to rate his or her overall wellness in each dimension on a scale of 1 to 10 , with 1 being very low and 10 representing a high level of wellness. With some clients, it may be helpful to ask for two ratings on a scale of 1 to 10 , the first being their perception of their overall wellness in an area, and the second being their level of satisfaction with their wellness in that area. We have found that some clients report mid- to low levels of wellness in an area and also report that they are quite content with their score at a particular time and have no desire for change. Of course, such statements are honored in the counseling process. Once clients have completed their self-ratings, we ask them to reflect on the scores to determine themes and patterns. In addition, we ask them to confirm that these ratings accurately depict how they see their wellness at this time.

In addition to or in place of an informal assessment, wellness in each dimension may be assessed using the Wellness Evaluation of Lifestyle (WEL; Myers, Sweeney, Witmer, \& Hattie, 1998), a paper-and-pencil measure that assesses each of the dimensions of wellness and provides composite scores for the tasks of self-direction as well as total wellness. The WEL has been normed on more than 4,000 people, including adolescents, young and mid-life adults, and older adults. Forms are available for use with adult populations and middle school children. Test-retest reliabilities range between .90 and .96 for all scales, and internal consistency coefficients range between .61 and .90 . The WEL has been studied using factor analysis as well as analyses of variance to determine the discriminatory power of the scales when working with people who are well and not well (Hattie et al., 1999).

Scores for the WEL are reported based on a linear transformation, with the highest possible score being 100 on all scales. Naturally, a scale score of 100 does not mean that additional enhancement is not possible (or needed due to the limitations of self-assessment). Profiles may be plotted showing graphically the relationship between scores on each dimension. Clients are encouraged to reflect on their scores, determine how representative the scores are of their total wellness (i.e., how well the scores reflect their perceptions of their total wellness), and then reflect on the pattern of their high and low scores. They are encouraged to select one or more of their low scores as areas for which they would like to develop a personal wellness plan. Alternately, clients may choose an area in which they received a high score, yet note this to be an area in which they would like to enhance their personal wellness. In all cases, we attempt to build on assets found in the profile by emphasizing attributes that can help to strengthen those found less satisfactory by the client. 


\section{Phase 3: Intentional Interventions to Enhance Wellness-Developing a Personal Wellness Plan}

Once wellness in each dimension has been assessed, either informally or formally, we ask our clients to choose one or more areas of wellness that they would like to change and improve. We do not recommend trying to effect change in all areas simultaneously, for two reasons. First, choosing to change in more than two to three areas is likely to represent an overwhelming array of tasks for anyone. Second, because change in one area will cause changes in other areas, awareness of wellness needs combined with change in any one area is likely to increase overall wellness and wellness in specific additional areas of the model.

Once the client identifies those dimensions that he or she would like to change in the direction of greater wellness, we work to coconstruct a personal wellness plan in each targeted area. The plan begins with a restatement of the definition of wellness for that particular dimension (the definitions included in this article may be useful to present to clients), followed by a rating scale consisting of the numbers 1 through 10 . The client is asked to circle the number reflecting their wellness in this area. We have developed a set of generic worksheets for use in this step of the process, an example of which is found in Appendix B. The client is asked to write comments on the worksheet concerning his or her satisfaction with self-rating. For clients with limited sight or other impairments, the counselor may offer to record their remarks. After a discussion of concerns related to their level of satisfaction, the client is asked to complete an informal self-assessment of personal strengths and limitations related to the wellness area targeted for change (see questions on worksheet in Appendix B).

The next step is the development of a written behavioral wellness plan. Included are objectives for change, methods to be used to effect change, and resources that will be used as the plan is implemented. If other people are to be involved in the plan in some way, that fact is noted. For example, if a client chooses to increase her level of exercise but does not enjoy exercising alone, we would discuss ways to select and involve a partner in the exercise plan.

\section{Phase 4: Evaluation and Follow-Up}

Finally, a discussion of evaluation procedures and timelines is an important part of the behavioral plan. The client should be encouraged to commit to an ongoing plan for regular and systematic evaluation, with identified markers that signify progress in making change. For wellness dimensions such as exercise, nutrition, and self-care, it will be easier to list and identify markers of change (e.g., exercised three times this week for 20 minutes each time, ate breakfast daily, lost 2 pounds per week). For other areas it may be more difficult to identify the process and products of the change process. We have found, for example, that feedback from friends and family is a good indicator that efforts to enhance one's sense of humor is having positive results, whereas feedback from the client is necessary to determine when cognitive techniques such as thought-stopping and challenging one's irrational thoughts are having an impact on irrational belief systems.

We encourage clients to develop both short- and longrange plans to improve their wellness. The counseling process can be a time to introduce them to the model; teach them techniques for self-assessment, planning, evaluation, and follow-up; and encourage them to develop a view of wellness as a lifelong process in which many changes will occur. We have found that many clients are able to develop and implement their own wellness plans after a short time, given only a blank worksheet, whereas others prefer a more focused, step-by-step process involving discussion with a professional. Some areas of wellness are popular in the media today, such as nutrition and exercise, and little outside intervention may be required to help a client experience positive change in these dimensions. Other areas, such as emotional awareness and coping and realistic beliefs, may benefit from traditional counseling interventions to facilitate change.

\section{CASE IUUSTMTION}

In most clinical practices, psychological assessment is used to ascertain indices of depression, personality disorder, and related attributes requiring therapeutic intervention. The use of the Wheel of Wellness Model and the WEL by clinicians has been gratifying because of their enthusiasm and that of their clients in finding a measure that focuses on positive attributes of health suitable for use in treatment planning. A client seen in the practice of one of the authors is presented here to exemplify the use of the Wheel in a clinical setting. Although it is beyond the scope of this article to provide a complete case and treatment plan, what follows are illustrations of how components of the model were incorporated into such a case from the perspective of an Adlerian counselor (Sweeney, 1998). The ethical guidelines of the American Counseling Association (ACA, 1995) were followed in developing this case illustration.

\section{Description of Client and Presenting Issue(s)}

Sylvia was a 24-year-old African American woman completing a master's degree in health and physical education at a mid-size university. She had been married 8 months earlier to her childhood sweetheart, who had a bachelor's degree in business and worked as a supervisor for the United Parcel Service. Within the past month, she had obtained full-time employment as a teacher and coach at a small liberal arts college. Three weeks before referral, she had learned that she was pregnant.

Sylvia was referred by her immediate supervisor who noticed that she seemed distracted and somewhat depressed. When asked about these behaviors, Sylvia reported feeling overwhelmed, stressed, and unable to concentrate. She was beginning to have arguments with her husband, whom she noted was thrilled about her pregnancy. She was "not happy" 
to be pregnant. After discovering that she was expecting a baby, Sylvia had "blown up" at her husband at least weekly. Since accepting her new job, she had been too busy to keep up with her friends, and she missed them. She had been short-tempered with her assistant coaches and found herself crying "for no reason" while driving to and from work.

\section{Counseling Interventions to Achieve the Wellness Plan}

Phase 1: Introduction of the Wheel of Wellness. After a standard intake interview in which she was asked to provide a psychosocial history, Sylvia was asked to reflect on her personal wellness. She noted that wellness to her meant being in good physical condition and not stressed and that she tried to stay well through exercise. She also noted that she was "very stressed" at that time and that she was not handling her stress well. I (Sweeney) provided Sylvia a copy of the Wheel of Wellness, explained the philosophy underlying the model, and reviewed the definitions of the components of the model. Several times during the discussion, Sylvia made comments such as "Oh, I am not well in that area at all." "I didn't realize that was part of wellness?" "I never thought about that before, but now that you mention it, I am not doing too well." It was noteworthy that she reported eating lots of high calorie snack foods and, at the same time, had not considered how or even if her diet would affect her developing child.

Phase 2: Informal and formal assessment. Sylvia was encouraged to assess her wellness informally as we discussed each component of the Wheel of Wellness. She expressed an interest in learning more about specific areas of her wellness by taking the WEL. In addition, I considered that the process of taking the WEL and reflecting on the individual items would increase her awareness of her wellness behaviors (or unwellness behaviors). The WEL was scored and a profile developed (see Figure 2) that graphically depicted relatively high scores on WORK, LOVE, and FRIENDSHIP as well as Sense of Humor, Exercise, Problem Solving and Creativity, Cultural Identity, and Gender Identity. She had low scores on SPIRITUALITY, LEISURE, and the following tasks of SELF-DIRECTION: Sense of Worth, Sense of Control, Realistic Beliefs, Nutrition, Self Care, and Stress Management.

Phase 3: Development of a personal wellness plan. Sylvia was encouraged to select one or, at most, two areas of wellness to focus on for improvement. She selected nutrition, mostly because of her pregnancy, and stress management. While working primarily on these goals, I noted that attention to realistic beliefs would be an important strategy for improving her total wellness. Sense of worth and sense of control, although not specifically addressed in the wellness plan, would also be facilitated through achievement of her goals as the plan was implemented. Following the authors' guideline to address no more than two or three dimensions at a time, I was convinced that the total plan would fail if the scope of change attempted was too broad to allow Sylvia to fully experience and appreciate success in the change pro- cess. One of our goals is to encourage a client and thereby facilitate self-efficacy through successive steps of improvement. This includes taking advantage of Sylvia's "assets" identified in the assessment: her sense of humor; her problem-solving attitudes and creativity; her love of physical activity; her network of friends; an intelligent, loving partner and family; and work that she believed challenged her capabilities.

An initial step in the development of a personal, behavioral wellness plan includes establishing baseline data. In terms of nutrition, Sylvia reported that she snacked constantly on chips and candy and drank at least four to six colas (not diet) daily. Because her husband often worked nights, they did not cook dinner and she would eat snacks for her evening meal. When asked about stress management, she indicated that her typical way of dealing with stress was to let it build up without doing anything about it until she became "like a pressure cooker that just has to let off steam." At that point she would blow up at her husband or another family member, preferring not to show her anger at work in case it affected her performance evaluations. For example, she stated that she never showed her temper with the players she coached, although "she pushed them pretty hard to do their best." This was especially important during the current probationary period on her job. Because she indicated a desire to work on stress management, we coconstructed a wellness plan in this area. It began in part, however, by uncovering unrealistic beliefs associated with stress.

For Sylvia, there were whatAdlerians call "biased apperceptions" about herself, others (especially her partner), life, and how she was to meet her responsibilities that were derived from a briefAdlerian life style assessment. Stress, anxiety, and depression were an outcome of thoughts that included "Winners wear the gold, losers are just losers"; "I don't like unexpected surprises-they mean trouble?"; "Men have it easier than women-and I don't like it!"; "Weak women are taken advantage of by others; therefore, I must be strong."

Stress management for Sylvia thus included confronting her "fictive notions" through thought-stopping and examination of ways to reframe circumstances as they are rather than as she expects them to become. Sylvia readily acknowledged that she held in her negative emotions until she had "exploded!"

After Sylvia had fully shared information about her predicament, she was asked to describe "a day in the future when she was relaxed, confident, and comfortable." She got teary-eyed and said she wasn't sure that she could. We paused for a moment, and then I asked if she would like to change the way her life was going. Although she readily said "yes," I explained that she may find changing her ways of thinking and responding more challenging than coaching a winning team. In this case, to be strong and not vulnerable meant leaning on those who care about you most and who experience you as a "winner" without competing for it. On the other hand, she had demonstrated a commitment to excellence in other important areas of her life, and she had those assets to draw on as her wellness plan was implemented.

Sylvia was helped to construct a stress management plan including objectives, methods, resources, timelines, and evalu- 


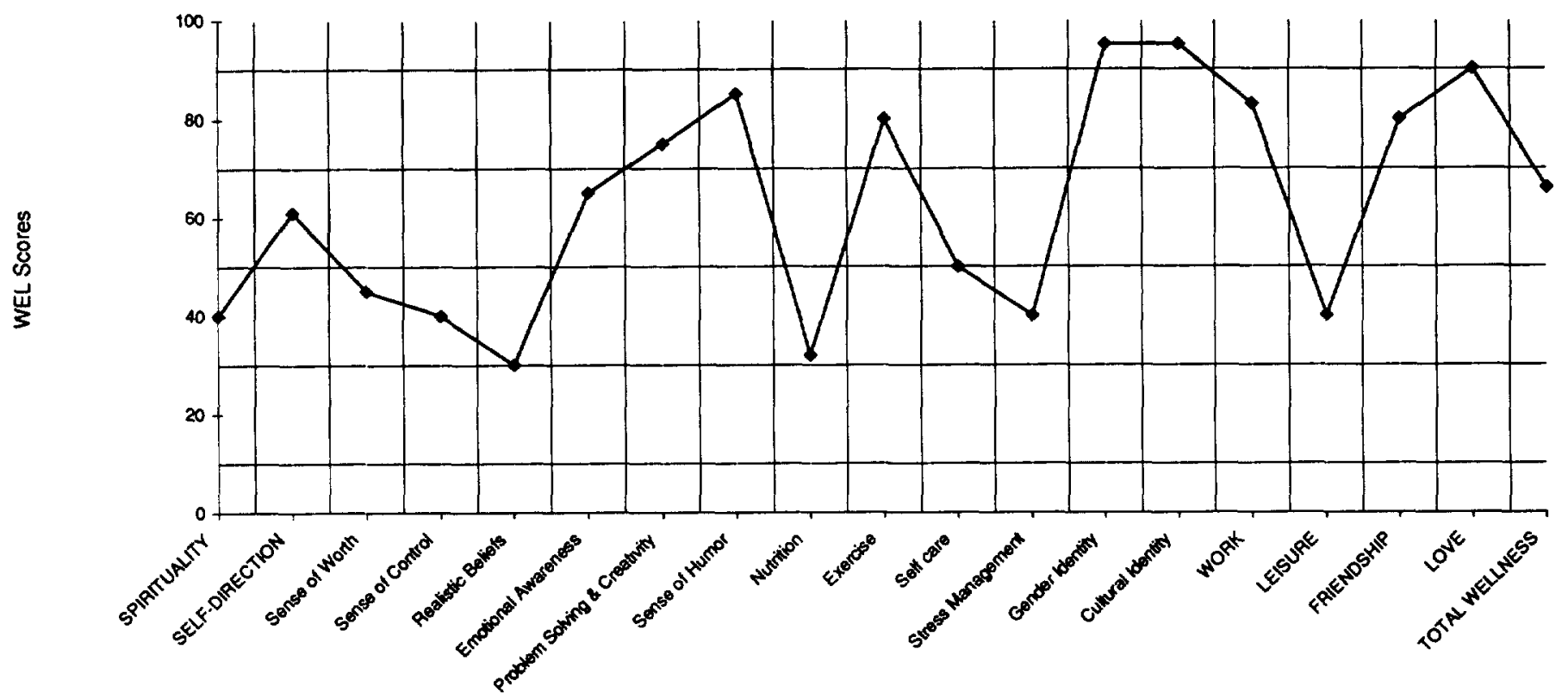

WEL Scales

FIGURE 2

\section{Profile of Wellness Evaluation of Lifestyle (WEL) Scores for Client Sylvia}

Note. Percentage scores of WEL Scales for Sylvia (age 25) are as follows: SPIRITUALITY $=40 ;$ SELF-DIRECTION $=61 ;$ Sense of Worth $=$ 45; Sense of Control = 40; Realistic Beliefs $=30$; Emotional Awareness $=65$; Problem Solving \& Creativity $=75$; Sense of Humor $=85$; Nutrition = 32; Exercise = 80; Self Care = 50; Stress Management = 40; Gender Identity = 95; Cultural identity = 95; WORK = 83; LEISURE = 40; FRIENDSHIP = 80; LOVE $=90 ;$ TOTAL WELLNESS $=66$.

ation. These included, for example, reestablishing a regular (three times per week minimum) program of exercises appropriate to her condition. She agreed to consult with a staff member in the college to guide her through this process over time. After stress-relaxation-response exercises experienced during counseling, she agreed to practice deep breathing exercises and positive imaging before, during, and after specific times known to be stressful for her (e.g., team practice sessions). She also agreed to keep a log of her responses, others' reactions, and her feelings related to these efforts.

The decision to choose nutrition and stress management to address in Sylvia's treatment plan presented an opportunity to consider the implications of working in areas not within one's competence. The Wellness model and, consequently, the WEL incorporate components drawn from research across disciplines. As a result, many counselors will wish to work collaboratively with professionals in other disciplines (e.g., a nutritionist) and continue their education in areas found needed by their clientele. In the case of Sylvia, the counselor had sufficient knowledge of basic nutritional guidelines to begin the process of helping Sylvia examine her nutritional habits. However, it also was de- cided that to ensure the best for the unborn child as well as mother, Sylvia needed to consult with her obstretician as a part of the information and planning process. As a consequence, a dietary plan, regular meals, supplements, and a schedule for visits to monitor weight and other physical indices of positive health were established for tracking throughout the pregnancy and beyond.

Phase 4: Evaluation and follow-up. The wellness plans that Sylvia developed included not only baseline data but also strategies, timelines, and techniques for assessing outcomes. The nutrition plan was far easier to develop, implement, and evaluate than was the plan for stress management. In effect, Sylvia agreed to keep a diary of her food intake, read articles, pamphlets, and web pages on nutrition-with a focus on nutrition during pregnancy - and take a course in natural-foods cooking. Her husband, mother, and sister agreed to help her plan meals, prepare grocery lists, and prepare nutritious meals. Her family and counselor made it a point to discuss with her the nutritional needs she would experience during her pregnancy to ensure that her baby would be healthy. In addition, her physician referred her to a nurse-dietician for consultation. 
After 6 weeks, Sylvia had made substantial changes in her daily food and nutrition intake and was determined to make those changes "lifelong." Sylvia's initial plan for stress management showed that she tended to have a "pressure cooker" explosion on the average of once a week. These were essentially eliminated during the first 6 weeks of implementing her wellness plan, supplemented with weekly counseling sessions. She used a relaxation tape made during one of the counseling sessions to practice between appointments, and she quickly learned the intrinsic satisfaction of control over her emotional outbursts. Her husband joined her for two counseling sessions in which they were both relieved to discover that each could express their fears, hopes, and aspirations for their career, family, and marriage with mutual support as a foundation.

\section{Concluding Comments}

Sylvia's case is rich with possibilities for creatively incorporating a new paradigm into the development of a treatment plan. It builds on assets such as her striving for excellence, self-efficacy, and interdependence with others. It challenges both counselor and client to think about greater possibilities for living life more fully, free of the "shoulds and oughts" found in her fictive beliefs, and offers renewed hope for greater wellness. More than repairing and supporting, it offers a plan for creating a new outlook on how to make the most of one's attributes, circumstances, and resources.

\section{conclusion}

The Wheel of Wellness incorporates 16 characteristics of healthy people, depicted graphically using four concentric circles and 12 spokes, identified through medical and psychosocial research as important components of wellness throughout the life span. This approach is solidly within the foundations of human development that are historically at the core of counselor education and practice in schools, colleges, and many agencies related to employment and rehabilitation. As both an enhancing and remedial intervention, counselors can assist clients in the process of assessing their wellness in components of the Wheel of Wellness and in developing wellness plans to facilitate positive growth and change across the life span. Additional research is needed to determine the most effective strategies for change to enhance wellness in each component of the model. Furthermore, although we know that the various dimensions of wellness interact and overlap, the extent to which some areas of the model are more closely related to, and thus more likely to have an impact on, other areas of the model has not been determined.

Research on the WEL and the Wheel of Wellness model will continue to offer new insights about cultural, gender, age, and other differences among individuals and groups of people in this country and abroad. Such data are of great interest to us. Our purpose in sharing our model at this time, however, is to provide a new way to conceptualize counseling for those whom we serve. Our goal is to help others to live long and well. We believe that this is the ultimate goal of effective counseling practice.

\section{REFERENCES}

Adams, R. G., \& Bleizner, R. (1995). Aging well with family and friends. American Behavioral Scientist, 39, 209-224.

Adler, A. (1954). Understanding human nature (W. B. Wolf, Trans.). New York: Fawcett Premier. (Original work published 1927)

Ali, N. S. (1996). Predictors of osteoporosis prevention among college students. American Journal of Health Promotion, 20, 379-388.

Allinger, R. L., \& Causey, M. E. (1995). Health concept of older Hispanic immigrants. Western Journal of Nursing Research, 17, 605-613.

American Counseling Association. (1995). ACA Code of ethics and standards of practice. Alexandria, VA: Author.

Ansbacher, H. L., \& Ansbacher, R. R. (1967). The individual psychology of Alfred Adler. New York: Basic Books.

Basow, S. A. (1992). Gender: Stereotypes and roles (3rd ed.). Monterey, CA: Brooks/Cole.

Baum, A., Herberman, H., \& Cohen, L. (1995). Managing stress and managing illness: Survival and quality of life in chronic disease. Journal of Clinical Psychology in Medical Settings, 2, 309-333.

Baumeister, R. F., \& Leary, M. R. (1995). The need to belong: Desire for interpersonal attachments as a fundamental human motivation. Psychological Bulletin, 117, 497-529.

Beckingham, A. C., \& Watt, S. (1995). Daring to grow old: Lessons in aging and empowerment. Educational Gerontology, 21, 479-495.

Benson, H., \& Stuart, E. M. (1992). The wellness book: The comprehensive guide to maintaining health and treating stress-related illness. New York: Simon \& Shuster.

Berkman, L., \& Syme, S. L. (1979). Social network, host resistance, and mortality: A nine-year study of Alameda County residents. American Joumal of Epidemiology, 109, 186-204.

Birkimer, J. C., Johnston, P. L., \& Berry, M. M. (1993). Guilt and help from friends: Variables related to healthy behavior. Joumal of Social Psychology, 133, 683-692.

Borenstein, L. (1996). The development of friendship in childhood: A clinical conversation. Child and Adolescent Social Work Joumal, 13, 213-222.

Branden, N. (1994). The six pillars of self-esteem. New York: Bantam.

Brandon, J. E., \& Loftin, J. M. (1991). Relationship of fitness to depression, state and trait anxiety, internal health locus of control, and selfcontrol. Perceptual and Motor Skills, 73, 563-568.

Broman, C. L. (1993). Social relationships and health-related behavior. Joumal of Behavioral Medicine, 16, 335-350.

Burg, M. M., \& Seeman, T. E. (1994). Families and health: The negative side of social ties. Annals of Behavioral Medicine, 16, 109-115.

Burke, R. J., \& McKeen, C. A. (1995). Work and career experiences and emotional well-being of managerial and professional women. Stress Medicine, 11, 51-60.

Burns, D. D. (1989). The feeling good handbook. New York: Penguin Group.

Carroll, J. L. (1990). The relationship between humor appreciation and perceived physical health. Psychology: A Joumal of Human Behavior, $27,34-37$.

Chandler, C. K., Holden, J. M., \& Kolander, C. A. (1992). Counseling for spiritual wellness: Theory and practice. Joumal of Counseling \& Development, 71, 168-175.

Chen, W. W. (1995). Enhancement of health locus of control through biofeedback training. Perceptual and Motor Skills, 80, 395-398.

Chumbler, N. R. (1996). An empirical test of a theory of factors affecting life satisfaction. Joumal of Psychology and Theology, 24, 220-232.

Cohen, S., \& Syme, S. L. (Eds.). (1985). Social support and health. London: Academic Press.

Coleman, D. J., \& Iso-Ahola, S. E. (1993). Leisure and health: The role of social support and self-determination. Joumal of Leisure Research, 25, 111-128.

Compton, W. C., Smith, L., Cornish, K. A., \& Qualls, D. L. (1996). Factor structure of mental health measures. Joumal of Personality and Social Psychology, 71, 406-413. 
Cooney, T. M., \& Kurz, J. (1996). Mental health outcomes following recent parental divorce: The case of young adult offspring. Joumal of Family Issues, 17, 495-513.

Covin, C. R., Block, J., \& Funder, D. (1995). Overly positive self-evaluations and personality: Negative implications for mental health. Journal of Personality and Social Psychology, 68, 1152-1162.

Cowen, E. L. (1991). In pursuit of wellness. American Psychologist, 46, 404-408.

Cowher, S. J. (1995). Recognizing and addressing gender issues in the classroom. Joumal of Humanistic Education and Development, 34, 35-4l.

Cramer, D. (1994). Self-esteem and Rogers' core conditions in close friends: A latent variable path analysis of panel data. Counseling Psychology Quarterly, 7, 327-337.

Cramer, S. R., Nieman, D. C., \& Lee, J. W. (1991). The effects of moderate exercise training on psychological well-being and mood state in women. Joumal of Psychosomatic Research, 35, 437-449.

Csikszentmihalyi, M. (1990). Flow. The psychology of optimum experience. New York: Basic Books.

Cvetanovski, J., \& Jex, S. M. (1994). Locus of control of unemployed people and its relationship to psychological and physical well-being. Work and Stress, 8, 60-67.

Dalgard, O. S., Bjork, S., \& Tambs, K. (1995). Social support, negative life events and mental health. British Journal of Psychiarry, 166, 29-34.

Daniels, K., \& Guppy, A. (1994). Occupational stress, social support, job control, and psychological well-being. Human Relations, 47, 1523-1544.

Davidson, S. L., \& Gilbert, L. A. (1993). Career counseling is a personal matter. The Career Development Quarterly, 42, 149-153.

Diener, E., \& Diener, M. (1995). Cross-culture correlates of life satisfaction and self-esteem. Joumal of Personality and Social Psychology, 69, 653-663.

Dillon, K. M., Minchoff, B., \& Baker, K. H. (1985). Positive emotional states and the enhancement of the immune system. International Journal of Psychiatry in Medicine, 15, 13-17.

Donaldson, S. L., \& Blanchard, A. L. (1995). The seven health practices, well-being, and performance at work: Evidence for the value of reaching small and underserved worksites. Preventive Medicine: An International Joumal Devoted to Practice and Theory, 24, 270-277.

Ebersoie, P., \& Hess, P. (1994). Toward healthy aging: Human needs and nursing response (4th ed.). St. Louis: Mosby.

Elliott, T. R., \& Marmarosh, C. L. (1994). Problem-solving appraisal, health complaints, and health-related expectancies. Joumal of Counseling \& Development, 72, 531-537.

Ellis, A (1973). Humanistic psychotherapy: The rational emotive approach. New York: Julian.

Ellis, A. (1984). Rational-emotive therapy. In R. J. Corsini (Ed.), Current psychotherapies (3rd ed., pp. 196-238). Itasca, IL: Peacock.

Encyclopedia of social work (19th ed.). (1995). Washington, DC: National Association of Social Workers.

Erdman, L. (1991). Laughter therapy for patients with cancer. Oncology Nursing Forum, 18, 1359-1363

Fontane, P. E. (1996). Exercise, fitness, and feeling well. American Behavioral Scientist, 39, 288-305.

Fontes, H. C. (1991). Celebrate your strengths. Activities, Adaptation, and Aging, 16, 39-47.

Gleser, J., \& Mendelberg, H. (1990). Exercise and sport in mental health: A review of the literature. Israel Joumal of Psychiatry and Related Sciences, 27, 99-112.

Goff, K. (1993). Creativity and life satisfaction in older adults. Educational Gerontology, 19, 241-250.

Golombok, S., \& Fivush, R. (1994). Gender development. New York: Cambridge University Press.

Green, J., \& Shellenberger, R. (1991). The dymamics of health and wellness: A biopsychosocial approach. Fort Worth, TX: Holt, Reinhart \& Winston.

Hafen, B. Q., Franksen, K. J., Karren, K. J., \& Hooker, K. R. (1992). The health effects of attitudes, emotional relationships. Provo, UT: EMS Associates.

Hartup, W. W., \& Stevens, N. (1997). Friendships and adaptation in the life course. Psychological Bulletin, 121, 355-370.

Hattie, J. A. (1992). Self-concept. Hillsdale, NJ: Erlbaum.

Hattie, J. A., Myers, J. E., \& Sweeney, T. J. (1999). A multidisciplinary model of wellness: The development of the wellness evaluation of lifestyle. Manuscript submitted for publication.

Hawes, E. C., \& Blanchard, L. M. (1993). Life tasks as an assessment technique in marital counseling. Individual Psychology, 49, 306-317.

Haworth, J. T., \& Hill, S. (1992). Work, leisure, and psychological wellbeing in a sample of young adults. Journal of Community and Applied Social Psychology, 2, 147-160.

Herr, E. L., \& Cramer, S. H. (1988). Career guidance and counseling through the lifespan. Glenview, IL. Scott, Foresman.

Hettler, W. (1984). Wellness: Encouraging a lifetime pursuit of excellence. Health Values: Achieving High Level Wellness, 8, 13-17.

Hinterkopf, E. (1994). Integrating spiritual experiences in counseling. Counseling and Values, 38, 165-175.

Hyuck, M. H. (1990). Gender differences in aging. In J. E. Birren \& K.W. Schaie (Eds.), Handbook of the psychology of aging (3rd ed., pp. 124132). San Diego, CA: Academic Press.

Ingersoll, R. E. (1994). Spirituality, religion, and counseling: Dimensions and relationships. Counseling and Values, 38, 98-111.

Ingram, R. E., Atkinson, J. H., Slater, M. A., Saccuzzo, D. P., \& Garfin, S. $R$. (1990). Negative and positive cognition in depressed and non-depressed chronic pain patients. Health Psychology, 9, 300-314.

International Society of Sport Psychology. (1992). Physical activity and psychological benefits: A position statement from the International Society of Sport Psychology. Joumal of Applied Sport Psychology, 4, 94-98.

Ishii-Kuntz, M. (1990). Social interaction and psychological well-being: Comparison across stages. International Joumal of Aging and Human Development, 30, 15-36.

Kaufmann, M.A. (1997). Wellness for people 65 years and better. Journal of Gerontological Nursing, 23, 7-9.

Keita, G. P., \& Jones, J. M. (1990). Reducing adverse reaction to stress in the workplace. American Psychologist, 10, 1137-1141.

Kiecolt-Glaser, J. K., Malarkey, W. B., Chee, M. A., Newton, T., Cacioppo, J. T., Mao, H. Y., \& Glaser, R. (1993). Negative behavior during marital conflict is associated with immunological down-regulation. Psychosomatic Medicine, 55, 395-409.

Kobasa, S. C. (1979). Stressful life events, personality, and health: An inquiry into hardiness. Joumal of Personality and Social Psychology, 37, $1-11$

Koenig, H. G. (1991). Religion and prevention of illness in later life. Prevention in Human Services, 10, 69-89.

Krystan, M., Moore, K. A., \& Zill, N. (1990). Identifying successful families: An overview of constructs and selected measures. Washington, DC: Child Trends.

Kuhnert, K. W., \& Palmer, D. R. (1991). Job security, health, and the intrinsic and extrinsic characteristics of work. Group and Organization Studies, 16, 178-192.

Kuiper, N. A., \& Martin, R. A. (1993). Humor and self-concept. Intemational Journal of Humor Research, 6, 251-270.

Kwan, V. S. Y., Bond, M. H., \& Singelis, T. M. (1997). Pancultural explanations for life-satisfaction: Adding relationship harmony to self-esteem. Joumal of Personality and Social Psychology, 73, 1038-1051.

Lam, P., Foong, Y. Y., \& Moo, S. N. (1995). Work life, career commitment, and job satisfaction as antecedents of career withdrawal cognition among teacher interns. Journal of Research and Development in Education, 28, 230-236.

Larson, D. D., \& Larson, S. S. (1991). Religious commitment and health: Valuing the relationship. Second Opinion: Health, Faith, and Ethics, 17, $26-40$.

Lawler, M. K., Volk, R. J., Viviani, N., \& Mengel, M. B. (1990). Individual and family factors impacting diabetic control in the adolescent: $A$ preliminary study. Matemal Child Nursing Joumal, 19, 331-345.

Lee, C. C. (1996). MCT theory and implications for indigenous healing. In D. W. Sue, A. E. Ivey, \& P. B. Pedersen (Eds.), A theory of multicultural counseling and therapy (pp. 86-98). Pacific Grove, CA: Brooks/Cole.

Lee, C. C. (1997) Multicultural issues in counseling (2nd ed.). Alexandria, VA: American Counseling Association.

Lightsey, O. R. (1996). What leads to wellness? The role of psychological resources in well-being. Counseling Psychologist, 24, 589-735. 
Lindgren, K. N., \& Coursey, R. D. (1995). Spirituality and serious mental illness: A two-part study. Psychosocial Rehabilitation Journal, 18, 93-111.

Lu, L., \& Shih, J. B. (1997). Sources of happiness: A qualitative approach. Journal of Social Psychology, 137, 181-188.

Luks, A. (1992). The healing power of doing good. New York: Fawcett Columbine.

Maccoby, E. E. (1990). Gender and relationships: A developmental account. American Psychologist, 45, 513-520.

Maher, M. F., \& Hunt, T. K. (1993). Spirituality reconsidered. Counseling and Values, 28, 21-28.

Martin, R. A., Kuiper, N. A., Olinger, L. J., \& Dance, K. A. (1993). Humor, coping with stress, self-concept, and psychological well-being. International Joumal of Humor Research, 6, 89-104.

Maslow, A. (1970). Motivation and personality (2nd ed.). New York: Harper \& Row.

May, K. M., \& Logan, C. R. (1993). Family type and the accomplishment of developmental tasks among college students. Joumal of College Student Development, 34, 397-400.

McCain, N. L., \& Smith, J. C. (1994). Stress and coping in the context of psychoneuroimmunology: $A$ holistic framework for nursing practice. Archives of Psychiatric Nursing, 4, 221-227.

McDaniels, C., \& Gysbers, N. C. (1992). Counseling for career development: Theories, resources, and practice. San Francisco: Jossey-Bass.

Melamed, S., Meir, E. I., \& Samson, A. (1995). The benefits of personality-leisure congruence: Evidence and implications. Joumal of Leisure Research, 27, 25-40.

Montague, A. (1981). Growing young. New York: McGraw-Hill.

Morreall, J. (1991). Humor and work. International Journal of Humor Research, 4, 359-373.

Myers, J. E., Sweeney, T. J., Witmer, J. M., \& Hattie, J. H. (1998). The Wellness Evaluation of Lifestyle-Form J. Manuscript submitted for publication.

Myers, J. E., Witmer, J. M., \& Sweeney, T. J. (1998). The WEL workbook. Unpublished manuscript.

Napholz, L. (1995). Indexes of psyschological well-being and role commitment among working women. Joumal of Employment Counseling, $32,22-31$.

Nelson, R. C., \& Franzi, L. R. (1989). Nutrition and aging. Medical Clinic of North America, 73, 1531-1550.

Nicholas, D. R., Gobble, D. C., Crose, R. G., \& Frank, B. (1992). A systems view of health, wellness, and gender: Implications for mental health counseling. Joumal of Mental Health Counseling, 14, 8-19.

Oleckno, W. A., \& Blacconiere, M. J. (1991). Relationship of religiousity to wellness and other health-related behaviors and outcomes. Psychological Reports, 68, 819-826.

Ornish, D. (1998). Love and survival: The scientific basis for the healing power of intimacy. New York: Harper Collins.

Ory, M. G., \& Cox, D. M. (1994). Forging ahead: Linking health and behavior to improve quality of life in older people. Social Indicators Research, 33, 89-120.

Pelletier, K. R. (1994). Sound mind, sound body: A new model for lifelong health. New York: Simon \& Shuster.

Perls, T. T., \& Silver, M. H. (1999). Living to 100: Lessons in living to your maximum potential at any age. New York: Basic Books.

Ragheb, M. G. (1993). Leisure and perceived wellness: A field investigation. Leisure Sciences, 15, 13-24.

Randall, J. L. (1996). Evolution of the new paradigm. Primary Care, 23 183-198.

Reitzes, D. C., Mutran, E. J., \& Verrill, L. A. (1995). Activities and selfesteem: Continuing the development of activity theory. Research on Aging, 17, 260-277.

Richman, J. (1995). The lifesaving function of humor with the depressed and suicidal elderly. Gerontologist, 35, 271-273.

Ross, C. E., \& Mirowski, J. (1996). Economic and interpersonal work rewards: Subjective utilities of men's and women's compensation. Social Forces, 75, 223-245.

Ryff, C. D., \& Heidrich, S. M. (1997). Experience and well-being: Explorations on domains of life and how they matter. The International Society for the Study of Behavioural Development, 20, 193-206.
Sarason, B. R., Shearin, E. N., Pierce, G. R., \& Sarason, I. G. (1987). Interrelations of social support measures: Theoretical and practical implications. Joumal of Personality and Social Psychology, 52, 813-832.

Seaward, B. L. (1995). Reflections on human spirituality for the worksite. American Joumal of Health Promotion, 9, 165-168.

Shannon, G. W., \& Pyle, G. F. (1993). Disease and medical care in the United States: $A$ medical atlas of the twentieth century. New York: Macmillan.

Shek, D. T. (1995). Marital quality and psychological well-being of married adults in a Chinese context. Joumal of Genetic Psycholooy, 156, 45-56.

Smith, H. B. (1997, October). Managed care and the counseling profession. Paper presented at the meeting of the Southern Association for Counselor Education and Supervision, Louisville, KY.

Solomon, J. C. (1996). Humor and aging well. American Behavioral Scientist, 39, 249-271.

Spence, J. T., \& Sawin, L. L. (1985). Images of masculinity and femininity: A reconceptualization. In V. E. O'Leary, R. K. Unger, \& B. S. Wallston (Eds.), Women, gender, and psychology (pp. 35-66). Hillsdale, NJ: Erlbaum.

Sternberg, S. (1997, September 10). Medicare gives preventive Ornish heart program a try. USA Today, Dl

Sue, D. W., \& Sue, D. (1990). Counseling the culturally different: Theory and practice (2nd ed.). New York: Wiley

Sweeney, T. J. (1998). Adlerian counseling: A practitioner's approach (4th ed.). New York: Taylor \& Francis.

Sweeney, T. J., \& Witmer, J. M. (1991). Beyond social interest: Striving toward optimal health and wellness. Individual Psychology, 47, 527-540.

Temoshok, L., \& Dreher, H. (1992). The Type C connection: The behavioral links to cancer and health. New York: Random House.

Thompson, M. G., \& Heller, K. (1990). Facets of support related to wellbeing: Quantitative social isolation and perceived family support in a sample of elderly women. Psychology and Aging, 5, 535-544.

Toner, H. M., \& Morris, J. D. (1992). A social-psychological perspective of dietary quality in later adulthood. Joumal of Nutrition for the Elderly, 11, 35-53.

Ulione, M. S. (1996). Physical and emotional health in dual-earner families. Family and Community Health, 19, 14-20.

U.S. Department of Health and Human Services. (1990). Healthy people 2000: National health promotion and disease prevention objectives. Washington, DC: U.S. Government Printing Office.

U.S. Department of Health and Human Services. (1996). Dietary guidelines for Americans. Home and Garden Bulletin, No. 232. Washington, DC: U.S. Government Printing Office.

Walcott-McQuigg, J. A., Sullivan, J., Dan, A., \& Logan, B. (1995). Psychosocial factors influencing weight control behavior of African American women. Western Journal of Nursing Research, 17, 502-520.

Walker, D., \& Beauchene, R. E. (1991). The relationship of loneliness, social isolation, and physical health to dietary adequacy of independent living elderly. Joumal of the American Dietetic Association, 91, 300-304.

Warr, P. (1994). A conceptual framework for the study of work and health. Work and Stress, 8, 84-97.

Westgate, C. E. (1996). Spiritual wellness and depression. Journal of Counseling \& Development, 75, 26-35

Whaley, A. L. (1993). Self-esteem, cultural identity, and psychosocial adjustment in African American children. Joumal of Black Psychology, $19,406-422$.

Winefield, H. R., Winefield, A. H., \& Tiggeman, M. (1992). Joumal of Personality Assessment, 58, 198-210.

Witmer, J. M. (1996). Reaching toward wellness: A holistic model for personal growth and counseling. Athens, $\mathrm{OH}$ : Author.

Witmer, J. M., \& Sweeney, T. J. (1992). A holistic model for wellness and prevention over the life span. Joumal of Counseling \& Development, $71,140-148$

Witmer, J. M., Sweeney, T. J., \& Myers, J. E. (1998). The wheel of wellness. Greensboro, NC: Authors

Wrzesniewski, A., McCauley, C., Rozin, P., \& Schwartz, B. (1997). Jobs, careers, and callings: People's relations to their work. Joumal of $R e-$ search in Personality, 31, 21-33.

Wurtman, J. J., \& Suffes, S. (1996). The serotonin solution. New York: Fawcett. Wykoff, W. (1993). The psychological effects of exercise on non-clinical 
and clinical populations of adult women: A critical review of the literature. Occupational Therapy in Mental Health, 12, 69-106.

Yau, C. (1991). An essential interrelationship: Healthy self-esteem and productive creativity. The Joumal of Creative Behavior, 25, 154-161.

Zauszniewski, J. A. (1994). Health-seeking resources and adaptive functioning in depressed and nondepressed adults. Archives of Psychiatric Nursing, 3, 159-168.

Zimmer, Z., \& Lin, H. S. (1996). Leisure activity and well-being among the elderly in Taiwan: Testing hypotheses in an Asian setting. Joumal of Cross Cultural Gerontology, 11, 167-186.

Zis, M., Jacobs, L. R., \& Shapiro, R. Y. (1996). The elusive common ground: The politics of public opinion and healthcare reform (Where is healthcare headed?). Generations, 20(6), 1-5.

\section{APPENDIX A}

\section{Dimensions of the Wheel of Wellness}

I. SPIRITUALITY-Personal and private beliefs that transcend the material aspects of life and give a deep sense of wholeness, connectedness, and openness to the Infinite.

A. Belief in a power beyond oneself

B. Hope and optimism, believing that things will work out for the best

C. Meaning and purpose that are a part of one's philosophy of life

D. Worship, prayer, meditation, or self-reflection in relationship to the Infinite

E. Love, compassion, and service to others

F. Moral and ethical values for guiding everyday life

G. Transcendence, going beyond the rational limits for insights or mystical experiences; frequently accompanied by a sense of timelessness, inner peace, harmony, or oneness with nature, the universe, or the Infinite

II. SELF-DIRECTION-The process that enables one to regulate and direct daily activities as well as pursue longrange goals through personal attributes.

A. Sense of Worth

1. Acceptance of self with one's imperfections and shortcomings

2. Feelings of adequacy

3. Recognition of positive qualities

B. Sense of Control

1. Beliefs about mastery, competence, self-confidence

2. Believing that certain desired outcomes are possible

3. Ability to be direct in expressing one's needs (assertiveness)

C. Realistic Beliefs

1. Ability to perceive truth and reality as they are rather than as one might wish it to be; recogniz ing the difference between realistic goals and ideals

2. Minimizing irrational beliefs such as having to always be perfect and having to be liked and loved by everyone

3. Being aware of, able to challenge, and to revise irrational thoughts, images, and self-talk that are selfdefeating

D. Emotional Awareness and Coping

1. Being able to experience a full range of emotions and being able to express them appropriately, both positive and negative

2. Able to recognize the emotions in others

3. Enjoying positive emotions and managing negative emotions

E. Problem Solving and Creativity

1. Being mentally active, open-minded; curiosity, need to know, desire to learn

2. Effective problem-solving and conflict-resolution skills for everyday events

3. Desire and willingness to express one's creative urges

F. Sense of Humor

1. Ability to laugh appropriately at oneself

2. Having the capacity to see the humor in the contradictions and predicaments in life, thus gaining a more objective or different perspective

3. Using humor to cope with one's own difficulties or mistakes

G. Nutrition

1. Eating meals regularly and including a variety of healthful foods for a balanced diet

2. Following a high fiber, low fat, low cholesterol diet with limited sodium and moderate sugar intake

3. Maintaining weight within the acceptable range

H.Exercise

1. Leading an active rather than sedentary lifestyle

2. Engaging in regular physical activities (at least three times a week) that develop endurance, flexibility, and strength

3. Seeking opportunities at home, at work, and in leisure activities to be physically active

I. Self-Care

1. Practicing good health habits such as adequate sleep and preventive medical and dental care

2. Practicing safety habits such as wearing a seatbelt and avoiding toxic agents in the environment

3. Refraining from using or abusing harmful substances such as alcohol, tobacco, and illegal drugs

J. Stress Management

1. Ongoing awareness and monitoring of the stressors in one's life

2. Perceiving events and change as a challenge rather than a threat to one's well-being; believing that life is manageable and meaningful

3. Using mental, emotional, physical, and behavioral methods to cope with stress

K. Gender Identity

1. Satisfaction with one's own gender orientation

2. Feeling supported in one's gender

3. Valuing relationships with both genders

L. Cultural Identity

1. Satisfaction with one's cultural background

2. Feeling supported in one's culture

3. Valuing relationships with persons of different cultures

III. WORK AND LEISURE-Work serves economic, psychological, and social purposes; leisure activities, whether 
physical, social, intellectual, creative, or volunteer, provide opportunity for intrinsic satisfaction.

A. Work

1. Perception of adequate financial reward for basic goods and services

2. Satisfactory challenges, coworker relations, and working conditions

3. Satisfaction comes primarily from the relationship between the work goals of the person and the rewards and opportunities in the work setting.

B. Leisure

1. Self-determined activities and experiences engaged in because of discretionary time and money

2. Positive feelings are associated with the physical, social, intellectual, creative, or volunteer activities chosen

3. By their very nature, leisure activities absorb the person in the flow of the activity so that the individual loses consciousness of time and self

IV. FRIENDSHIP-All those social relationships that involve connection with others either individually or in community, but do not have a marital, sexual, or familial commitment

1. Having social support when needed or desiredmaterial, emotional, and informational

2. Being able to give social support to others through friendships and volunteer activities
3. Having the basic social skills that give a sense of comfort when in social settings and while interacting with others, one on one or in small groups

4. A sense of connectedness to something beyond oneself and that one is not alone in sharing and facing life events V. LOVE-Includes those relationships that are intimate, trusting, self-disclosing, cooperative, compassionate, and usually long-term in commitment; usually few in number from family and significant others

1. Trust, intimacy, caring, and companionship in a relationship that is reciprocal

2. Romance, passion, and sexual relations may be part of the relationship

3. Having at least one person who has a continuing interest in one's growth and well-being

4. Healthy love relationships have the ingredients of commitment, shared interests and values, time together, mutual appreciation and affection, good communication, and problem-solving, conflict-resolution skills

Note. Adapted from The WEL Workbook (pp. 8-9), J. E. Myers, J. M. Witmer, and T. J. Sweeney, unpublished manuscript. Copyright 1998. Adapted with permission by J. E. Myers, J. M. Witmer, and T. J. Sweeney.

\title{
APPENDIX B
}

\section{Life Challenge Worksheet: Self-Direction-Sense of Humor}

\begin{abstract}
Humor, particularly when it is accompanied by laughter, promotes physiological, psychological, and social change. It creates an open flexibility for problem solving, reduces defensiveness, and improves communication while neutralizing stress. Having a sense of humor means you can laugh at your own mistakes and the unexpected things that happen to you. You laugh with others rather than at them, being sensitive to their own self-esteem. You can be playful even when engaging in serious tasks. Humorous situations are sought in media such as cartoons, comedies, and the comics. Playful and humorous exchanges are frequently a part of the interaction with others. Life events from your own experiences and from the daily news can be seen in a humorous light.
\end{abstract}

Circle the number on the scale below that reflects your perceptions of wellness related to your sense of humor.

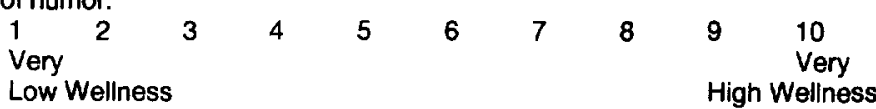

What are your personal strengths and limitations relative to your sense of humor?

Strengths:

Limitations:

Wellness Plan for Sense of Humor:

Goals:

Methods:

Resources: 